\title{
The Think A-Head campaign: an introduction to Image Gently 2.0
}

\author{
Donald P. Frush ${ }^{1}$ - Lee S. Benjamin ${ }^{2}$ - Nadia Kadom ${ }^{3}$ - Charles G. Macias ${ }^{4}$. \\ Sally K. Snow ${ }^{5} \cdot$ Sarah J. Gaskill $^{6}$ • Emilee Palmer $^{7}$ - Keith J. Strauss ${ }^{8}$. \\ The Think A-Head Campaign Committee
}

Received: 7 October 2016 / Accepted: 19 October 2016/Published online: 4 November 2016

(C) Springer-Verlag Berlin Heidelberg 2016

\section{Introduction}

A decade has passed since the inception of the Alliance for Radiation Safety in Pediatric Imaging [1]. This milestone marks a good time for a look back at what has been accomplished and what needs to be changed. Specifically, this commentary could comprise what has been achieved, what kind of impact the campaign has made on radiation safety in pediatric

Donald P. Frush

donald.frush@duke.edu

1 Department of Radiology, Duke University Medical Center, 1905 McGovern-Davison Children's Health Center, Durham, NC 27710, USA

2 Department of Emergency Medicine, St. Joseph Mercy Health System, Ann Arbor, MI, USA

3 Department of Radiology and Imaging Science, Emory University School of Medicine, Atlanta, GA, USA

4 Department of Pediatrics, Baylor College of Medicine, Texas Children's Hospital,

Houston, TX, USA

5 Trauma Program, Cook Children's Medical Center, Ft. Worth, TX, USA

6 Department of Neurosurgery and Brain Repair, University of South Florida,

Tampa, FL, USA

7 OhioHealth, Westerville Medical Campus, Westerville, OH, USA

8 Department of Radiology, Cincinnati Children's Hospital Medical Center, Cincinnati, OH, USA imaging and also, importantly, what missed opportunities or missteps have occurred that we can learn from. But the Alliance from the outset has been about moving ahead, sometimes intensely focused and sometimes with a broad visionary brush. The Alliance has focused on what is next and why this is important, and in the end, how to improve imaging care of children. The six campaigns of Image Gently illustrate this effort. These campaigns have primarily addressed modalities - computed tomography, radiography, fluoroscopy, nuclear medicine, interventional fluoroscopy, and most recently, dental imaging. The message, the messengers, and messaging [2] were the basis of these campaigns, and the campaigns have been a vehicle for education. The most recent campaign of Image Gently was rolled out Nov. 2, 2016. This campaign is the Think A-Head campaign for imaging children with minor closed head injury. What does this campaign tell us about the next 10 years of the Alliance? The answer comes from highlighting select changes, successes and challenges of the last 10 years and using these to understand the emphasis for the next 10 years, essentially Image Gently 2.0. This look back, then, will be a basis for the look ahead.

A few operational and governance clarifications have occurred. The first deals with the branding of Image Gently. While the title Alliance for Radiation Safety in Pediatric Imaging was defensible as a name and made sense 10 years ago, the Alliance leadership thought it was time for a new name that reflects the evolved mission and role of the campaign. As a first formal announcement, the Alliance for Radiation Safety in Pediatric Imaging, an aptly descriptive name, is now officially the Image Gently Alliance. People recognize the phrase Image Gently and use it in conversations and other communications, so this change resonates. The new message and branding is more simple, direct, and now emblematic. The second change was made because progress thrives with innovation, effort 
and consensus. This comes from people. So to this end, the Alliance steering committee has also expanded its leadership representation to include parent advocates, community practice radiologists, and adult imagers.

The message has also evolved. Early campaigns were primarily focused on the radiation protection tenet of appropriate dose management. Now the Alliance message has a grown from that predominantly dose-reduction foundation to one of dose management, with an emphasis on appropriate and informed use, and on the value of the imaging findings [2, 3]. In the early days, one pressing need was to look critically at what we were doing, for example in excessive radiation from CT examinations, and this examination was fueled by a number of sources in both the medical literature and lay news media [4-8]. This recognition of radiation dose is still important, but it is now embedded within a more collective spectrum of responsibilities we have when imaging children. Promoting doing less has grown to a message of doing it right.

Doing it right involves another main tenet of radiation protection in medicine, which is, of course, justification: the examination is only performed when it is of value (recognizing that this is debated and quite complex $[9,10])$. Justification, sometimes called appropriateness, is a shared responsibility, whereas management is primarily the responsibility of the imaging community: technologists, radiologists and other imaging experts outside of the specialty of radiology, as well as medical physicists, all working as a team. When to order the study is a worthwhile direction to pursue. The most effective dose management strategy (considering all factors, such as radiation dose, money, equipment use) is avoiding a study that is of low value. We will return to this when discussing the Think A-Head campaign later in this paper.

Additionally, the growth of parallel missions, with like goals, is occurring. This began in 2009 with Image Wisely [11], a close and valued partner, and more recently has been evidenced through EuroSafe, Japan Safe Imaging, Canada Safe Imaging, AFROSAFE and LatinSAFE (Fig. 1). This has resulted in global messaging, networking and dialogue about responsibilities and actions. This growth brings opportunities, but also challenges, such as redundant efforts in a setting of limited campaign resources.

Increased recognition of the Image Gently model and brand [2] has also created opportunities to partner in development of regulation, guidance, accreditation, trade and other influences on health care related to imaging of children. The Alliance has established organizational relationships and input on documents and proposals with the Food and Drug Association, Environmental Protection Agency, the Joint Commission (TJC) [12] and the Medical Imaging \& Technology Alliance. This place at the table is welcomed and contributory. One recent example of Image Gently Alliance input involved a TJC proposal of a national patient safety goal that included imaging of head injury in

Fig. 1 Logos of a consortium of current radiation education/ protection campaign organizations
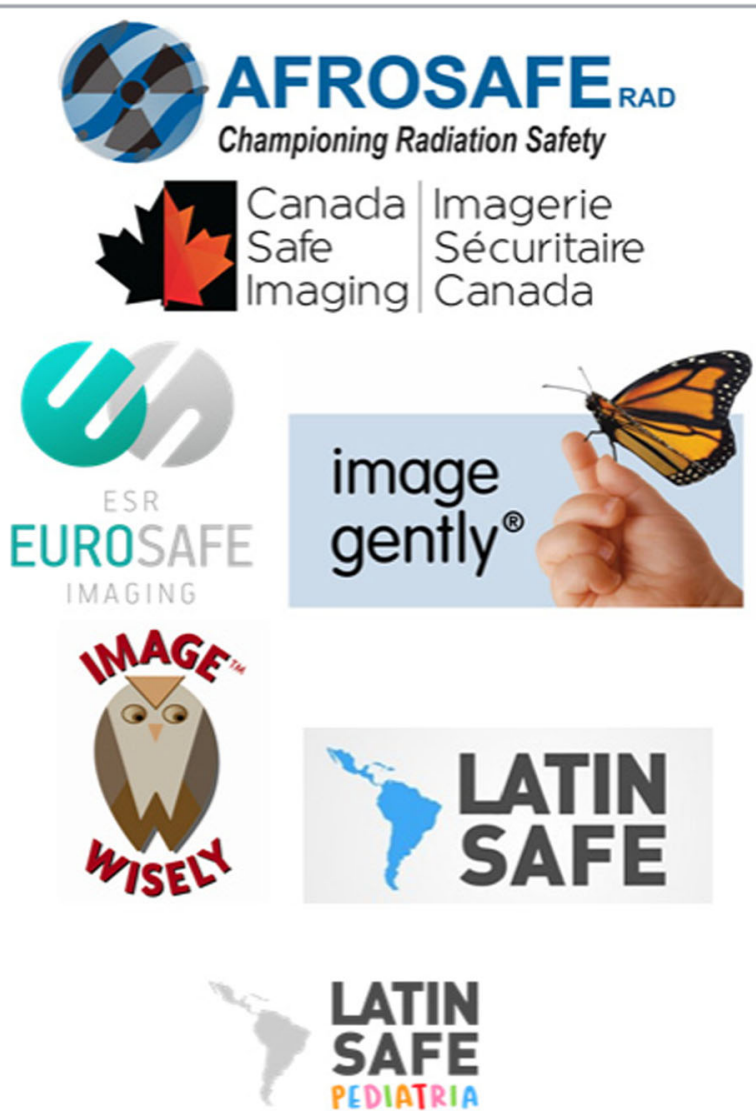
children. Alliance leaders had frequent and transparent discussion with engaged TJC leaders, and after field review, the TJC initiative was dropped. Image Gently leaders agreed that some of the observations of TJC were accurate, but other premises in the stewardship to improve imaging care fell more under the responsibility of a non-accrediting organizations such as Image Gently; some of these guidelines, in fact, were certainly harmonious with work on the new Alliance campaign, Think A-Head. A second example of partnership and contribution involved a Consumer Reports article on CT use and potential risk [13], with frequent broadcasts through various media outlets. Leadership from the American College of Radiology, Image Wisely, National Council on Radiation Protection and Measurements, and Image Gently (an illustration of the value of a close Alliance) proactively visited the Consumer Reports headquarters in Yonkers, New York. A very engaging and productive conversation about facts of radiation risk and improved clarity of public communication fostered a much improved understanding of what should be conveyed and how.

These experiences have all shaped the focus of the Alliance's newest campaign. The changes made — simplifying the name/branding, clarifying the message of radiation management, expanding representative leadership, embarking on justification in radiation protection, and leveraging the growing recognition of Image Gently both in the United States and globally - were highlighted to set the stage for the Think A-Head campaign.

Head trauma is frequent in children [14, 15]. CT is used frequently to diagnose the child's condition and can be extremely helpful [16-21]. Head CT is in fact is the most common CT examination performed in children $[22,23]$, accounting for $5-11 \%$ of examinations performed across all ages [22-26]. The frequency of head CT varies, as does the performance and resultant radiation dose estimations across ages [26-29]. In addition, there is variability in adherence to best practice clinical guidelines [30-34]. The issue of head CT and cancer risk is debated [35-41]; parental as well as emergency department providers' understanding of medical radiation exposure and cancer risk can vary [42-45]. Emergent care involves multiple stakeholders, including the patient and family, primary care physicians; nurses; emergency medicine physicians; trauma, pediatric and neurosurgeons; and the imaging team. These groups have different roles, perspectives and challenges in delivering their focused care. CT, then, is a common examination occurring in a setting of head trauma, which is stressful $[46,47]$ (you only have to mention the word "concussion"), and recognized public concern and confusion over both loosely defined paths in care and potential radiation risk. This is exactly portfolio that Think A-Head is addressing. It is worth mentioning that this effort has also been embraced by
Choosing Wisely, which is aimed at reducing unnecessary procedures (and both Image Gently and Image Wisely have been recognized as influencers in the Choosing Wisely campaign) [48].

So how does Think A-Head provide a narrative based on the changes in the Alliance noted previously? Let us look at the campaign message, messengers and messaging. The campaign message is simple, resonant and has a reasonable translation across stakeholders — parents/public, clinical practitioners and the imaging team, as well as other experts involved in the care of the child. This is a new venture into appropriateness and is not limited to the domain of radiology. The messengers (campaign committee) are pediatric radiologists, neuroradiologists, pediatric trauma surgeons, pediatric neurosurgeons, nurses, pediatricians, emergency medicine providers and communications experts. Additional messengers such as family practitioners could have been added. This exclusion was not intentional. Fundamentally, more diverse groups are sometimes difficult to convene.

The partner organizations are on the poster (Fig. 2) and in Table 1. Dialogue among committee members has been frequent, open and sometimes critical, but always respectful and forged to keep on task. Discussions on justification require this consensus. Problems with partial consensus have been difficult [49]. The communication aspect is quintessential. Orchestration of messengers and messaging is critical when dealing with organizations in the Alliance that have a combined representation of more than $1,000,000$ professionals. To this end, formation of an ad hoc communications committee has been much more important than in previous campaigns. The message must be harmonious within each constituent. Shawn Farley (American College of Radiology) and Greg Morrison (American Society of Radiologic Technologists), two long-standing steering committee members, have been invaluable to this end.

Other articles will deal with specifics of the Think A-Head campaign, focusing on the value of appropriateness and quality improvement $[50,51]$, including use of evidence-based guidelines (e.g., PECARN [52]) and head CT techniques for children $[53,54]$. There will be continued dialogue about risk potential and communication, which we recognize will sometimes be challenging but is clearly essential [23, 46, 55, 56]. Pediatric Radiology as a journal has provided a home to the Alliance from the very origins by publishing more than 10 articles specifically addressing Image Gently. Pediatric Radiology has been a consistent portal for communication by and about Image Gently. This support has been in no small part instrumental in the successes of the Alliance. So the Image Gently Alliance continues to look ahead, to listen, and to change when needed. Image Gently 2.0 is the next 10 years. What has not changed is the unity in purpose through the use of heads, hands and hearts by so many to achieve informed, compassionate and expert imaging care of children. 
Fig. 2 The Think A-Head campaign poster
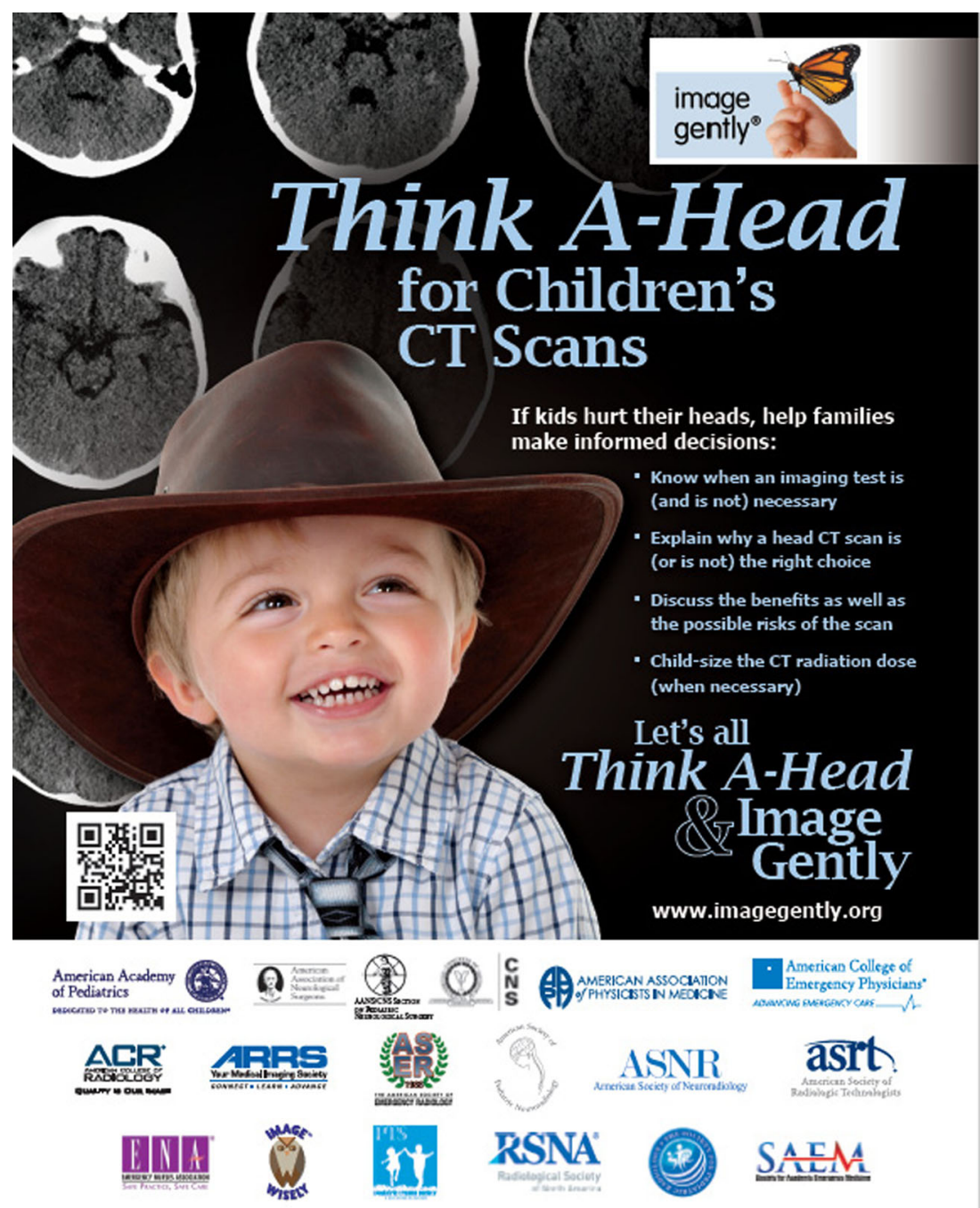

Table 1 Organizations listed on the Image Gently Alliance Think AHead campaign poster supporting the poster message

American Academy of Pediatrics

American Association of Neurological Surgeons and Congress of

Neurological Surgeons (Joint Section) on Pediatric Neurological Surgery

American Association of Physicists in Medicine

American College of Emergency Physicians

American College of Radiology

American Roentgen Ray Society

American Society of Emergency Radiology

American Society of Pediatric Neuroradiology

American Society of Neuroradiology

American Society of Radiologic Technologists

Emergency Nurses Association

Image Wisely

Pediatric Trauma Society

Radiological Society of North America

Society for Pediatric Radiology

Society for Academic Emergency Medicine

These organizations support/endorse/participate in the principles of the campaign as listed on the Think A-Head poster, not necessarily other campaign-based content, such as in publications or presentations
Compliance with ethical standards

Conflicts of interest None

\section{References}

1. Goske MJ, Applegate KE, Frush DP et al (2008) The Image Gently campaign: increasing CT radiation dose awareness through a national education and awareness program. Pediatr Radiol 38:265269

2. Strauss KJ, Frush DP, Goske MJ (2015) Image Gently campaign: making a world of difference. Med Phys Int 3:94-108

3. Frush DP (2016) Reply to Dr. Andronikou: holding on to informed use of diagnostic imaging using ionizing radiation. Pediatr Radiol [In press]

4. Cohen MD (2015) ALARA, Image Gently and CT-induced cancer. Pediatr Radiol 45:465-470 
5. Sternberg S (2001) CT scans in children linked to cancer later. USA Today. http://usatoday30.usatoday.com/news/nation/2001-01-22scans.htm. Accessed 14 Oct 2016

6. Redberg RF, Smith-Bindman R (2014) We are giving ourselves cancer. The New York Times. http://www.nytimes.com/2014/01 /31/opinion/we-are-giving-ourselves-cancer.html. Accessed 4 Oct 2016

7. Bogdanich W, Rebelo K (2011) X-rays and unshielded infants. The New York Times. http://www.nytimes.com/2011/02/28/health/28 radiation.html. Accessed 4 Oct 2016

8. Bogdanich W, Craven McGinty J (2011) Radiation worries for children in dentists' chairs. The New York Times. http://www. nytimes.com/2010/11/23/us/23scan.html. Accessed 4 Oct 2016

9. Frush DP (2014) Deciding why and when to use CT in children: a radiologist's perspective. Pediatr Radiol 44:404-408

10. Levin DC, Rao VM (2016) Factors that will determine future utilization trends in diagnostic imaging. J Am Coll Radiol 13:904-908

11. Brink JA, Amis ES (2010) Image Wisely: a campaign to increase awareness about adult radiation protection. Radiology 257:601602

12. The Joint Commission (2015) Diagnostic imaging requirements. The Joint Commission. http://www.jointcommission.org/assets/1 /18/AHC_DiagImagingRpt_MK_20150806.pdf. Accessed 4 Oct 2016

13. Consumer Reports (2015) Radiation risks. The surprising dangers of CT scans and $\mathrm{x}$-rays: patients are often exposed to cancer-causing radiation for little medical reason, a Consumer Reports investigation finds. Consumer Reports. http://www.consumerreports. org/cro/magazine/2015/01/the-surprising-dangers-of-ct-sans-andX-rays/index.htm. Accessed 4 Oct 2016

14. Maguire JL, Boutis K, Uleryk EM et al (2009) Should a headinjured child receive a head CT scan? A systematic review of clinical prediction rules. Pediatrics 124:e145-e154

15. Huisman TAGM, Poretti A (2016) Trauma. In: Masdeu JC, Gonzalez RG (eds) Handbook of clinical neurology, vol. 136 (3rd series), Neuroimaging, part II. Elsevier, Atlanta

16. Larson DB, Johnson LW, Schnell BM et al (2011) National trends in CT use in the emergency department: 1995-2007. Radiology 258:164-173

17. Korley FK, Pham JC, Kirsch TD (2010) Use of advanced radiology during visits to US emergency departments for injury-related conditions, 1998-2007. JAMA 304:1465-1471

18. Roudsari BS, Psoter KJ, Vavilala MS et al (2013) CT use in hospitalized pediatric trauma patients: 15-year trends in a level I pediatric and adult trauma center. Radiology 267:479-486

19. Macias CG, Sahouria JJ (2011) The appropriate use of CT: quality improvement and clinical decision-making in pediatric emergency medicine. Pediatr Radiol 41:S498-S504

20. Ryan ME, Palasis S, Saigal G et al (2014) ACR appropriateness criteria head trauma — child. J Am Coll Radiol 11:939-947

21. Hricak H, Brenner DJ, Adelstein SJ et al (2011) Managing radiation use in medical imaging: a multifaceted challenge. Radiology 258: 889-905

22. Wildman Tobriner B, Chatfield M, Behnke ES, Frush DP (2014) ACR dose index registry. A resource for pediatric CT practice assessment and radiation dose estimations. Radiological Society of North America Annual Meeting 2014, Chicago

23. Perez M (2016) Expert working group. Communicating radiation risks in paediatric imaging: information to support healthcare discussions about benefit and risk. World Health Organization. http://www.who.int/ionizing radiation/pub meet/radiation-riskspaediatric-imaging/en/. Accessed 4 Oct $201 \overline{6}$

24. Dorfman AL, Fazel R, Einstein AJ et al (2011) Use of medical imaging procedures with ionizing radiation in children: a population-based study. Arch Pediatr Adolesc Med 165:458-464
25. Mettler FA, Wiest PW, Locken JA et al (2000) CT scanning: patterns of use and dose. J Radiol Prot 20:353-359

26. Miglioretti DL, Johnson E, Williams A et al (2013) The use of computed tomography in pediatrics and the associated radiation exposure and estimated cancer risk. JAMA Pediatr 167:700-707

27. Graves JM, Kanal KN, Vavilala MS et al (2014) Hospital-level factors associated with use of pediatric radiation dose-reduction protocols for head CT: results from a national survey. J Am Coll Radiol 11:717-724

28. Smith-Bindman R, Lipson J, Marcus R et al (2009) Radiation dose associated with common computed tomography examinations and the associated lifetime attributable risk of cancer. Arch Intern Med 169:2078-2086

29. Lodwick DL, Cooper JN, Kelleher KJ et al (2015) Variation in utilization of computed tomography imaging at tertiary pediatric hospitals. Pediatrics 136:e1-e8

30. Hendee WR, Becker GJ, Borgstede JP et al (2010) Addressing overutilization in medical imaging. Radiology 257:240-245

31. Kanzaria HK, Hoffman JR, Probst MA et al (2015) Emergency physician perceptions of medically unnecessary advanced diagnostic imaging. Acad Emerg Med 22:390-398

32. Studdert DM, Mello MM, Sage WM et al (2005) Defensive medicine among high-risk specialist physicians in a volatile malpractice environment. JAMA 293:2609-2617

33. Griffey RT, Jeffe DB, Bailey T (2014) Emergency physicians' attitudes and preferences regarding computed tomography, radiation exposure, and imaging decision support. Acad Emerg Med 21: 768-777

34. Linscott LL, Kessler MM, Kitchin DR et al (2013) CT for pediatric, acute, minor head trauma: clinician conformity to published guidelines. AJNR Am J Neuroradiol 34:1252-1256

35. Mathews J, Forsythe A, Brady Z et al (2012) Cancer risk in 680,000 people exposed to computed tomography scans in childhood or adolescence: data linkage study of 11 million Australians. BMJ 346:1-18

36. Huang WY, Muo CH, Lin CY et al (2014) Paediatric head CT scan and subsequent risk of malignancy and benign brain tumour: a nation-wide population-based cohort study. Br J Cancer 110: 2354-2360

37. Pearce MS, Salotti JA, Little MP et al (2012) Radiation exposure from CT scans in childhood and subsequent risk of leukemia and brain tumors: a retrospective cohort study. Lancet 380:499-505

38. Krille L, Dreger S, Schindel R et al (2015) Risk of cancer incidence before the age of 15 years after exposure to ionising radiation from computed tomography: results from a German cohort study. Radiat Environ Biophys 54:1-12

39. Journy N, Rehel JL, Ducou Le Pointe H et al (2015) Are the studies on cancer risk from CT scans biased by indication? Elements of answer from a large-scale cohort study in France. Br J Cancer 112:185-193

40. Boice JD (2015) Radiation epidemiology and recent paediatric computed tomography studies. Ann ICRP 44:236-248

41. McCollough CH, Bushberg JT, Fletcher JG et al (2015) Answers to common questions about the use and safety of CT scans. Mayo Clin Proc 90:1380-1392

42. Boutis K, Cogollo W, Fischer J et al (2013) Parental knowledge of potential cancer risks from exposure to computed tomography. Pediatrics 132:305-311

43. Lam DL, Larson DB, Eisenberg JD et al (2015) Communicating potential radiation-induced cancer risks from medical imaging directly to patients. AJR Am J Roentgenol 205:962-970

44. Ditkofsky N, Shekhani HN, Cloutier M et al (2016) Ionizing radiation knowledge among emergency department providers. J Am Coll Radiol 13:1044-1049 
45. Steele JR, Jones AK, Clarke RK et al (2016) Oncology patient perceptions of the use of ionizing radiation in diagnostic imaging. J Am Coll Radiol 13:768-774

46. Broder JS, Frush DP (2014) Content and style of radiation risk communication for the pediatric patients. J Am Coll Radiol 11: 238-242

47. Frush DP, Frush KS (2008) 'Sleeping with the enemy?' Expectations and reality to imaging children in the emergency setting. Pediatr Radiol 38:S633-S638

48. Wolfson D (2016) Letter to the editor: radiation story. The Washington Post. https://www.washingtonpost.com/national/health-science/letterto-the-editor-radiation-story/2016/01/11/45bf45ac-b4a9-11e5-a76a0b5145e8679a_story.html. Accessed 4 Oct 2016

49. Sierzenski PR, Linton OW, Frush DP et al (2014) Applications of justification and optimization in medical imaging: examples of clinical guidance for computed tomography use in emergency medicine. J Am Coll Radiol 11:36-44

50. Nigrovic LE, Stack AM, Mannix RC et al (2015) Quality improvement effort to reduce cranial CTs for children with minor blunt head trauma. Pediatrics 136:e227-e233

51. Fabio Paolicchi F, Faggioni L, Bastiani L (2014) Optimizing the balance between radiation dose and image quality in pediatric head
CT: findings before and after intensive radiologic staff training. AJR Am J Roentgenol 202:1309-1315

52. Kuppermann N, Holmes JF, Dayan PS et al (2009) Identification of children at very low risk of clinically-important brain injuries after head trauma: a prospective cohort study. Lancet 374:1160-1170

53. American Association of Physicists in Medicine (2015) Routine pediatric head (brain). American Association of Physicists in Medicine. https://www.aapm. org/pubs/CTProtocols/documents/PediatricRoutineHeadCT. pdf. Accessed 4 Oct 2016

54. Image Gent ly Alliance (2014) Image Gently development of pediatric CT protocols 2014. Image Gently. http://www.imagegently. org/Portals/6/Procedures/IG\%20CT\%20Protocols\%20111714.pdf. Accessed 4 Oct 2016

55. Shyu JY, Sodickson AD (2016) Communicating radiation risk to patients and referring physicians in the emergency department setting. Br J Radiol 89:20150868

56. Robey TE, Edwards K, Murphy MK (2014) Barriers to computed tomography radiation risk communication in the emergency department: a qualitative analysis of patient and physician perspectives. Acad Emerg Med 21:122-129 